\title{
Catastrophic response of lakes to benthivorous fish introduction
}

\author{
Luis Zambrano, Marten Scheffer and Miguel Martínez-Ramos
}

Zambrano, L., Scheffer, M. and Martínez-Ramos, M. 2001. Catastrophic response of lakes to benthivorous fish introduction. - Oikos 94: 344-350.

\begin{abstract}
Introduction of the benthivorous common carp (Cyprinus carpio) has been identified as one of the main causes of loss of biodiversity and water clarity in numerous shallow lakes and ponds worldwide. Recent observations in experimental fish ponds suggest that the effect of carp on the ecosystem is catastrophic in the sense that a substantial impact occurs only when a critical carp density is exceeded. In search for an explanation, we analyzed a simple model of the interaction between benthivorous fish and their invertebrate benthic prey, and of sediment resuspension resulting from fish feeding behavior. Our results suggest that benthic prey populations should be only moderately depressed until predator fish abundance grows to a critical biomass at which benthos collapses due to overexploitation. This drop in prey density is predicted to result in a sharp increase in water turbidity due to an increase in prey search activity of the fish. For less eutrophic and deeper lakes, where benthos productivity and hence benthivorous fish carrying capacity are lower, water turbidity is predicted to be much less affected. The qualitative patterns are quite robust against assumptions on parameter values and correspond closely to the experimental results and data from lakes suggesting that the model may capture the essence of the mechanism causing a discontinuous effect of benthivorous fish on lake ecosystems.
\end{abstract}

L. Zambrano and M. Scheffer, Dept of Aquatic Ecology and Water Quality Management, Agricultural Univ. Wageningen, P.O. Box 8080, NL-6700 DD Wageningen, The Netherlands (present address of LZ: Departamento de Zoología, Instituto de Biología, UNAM, Apdo. Post 70-153 C.P. 04510, México D.F., Mexico [zambrano@ ibiologia.unam.mx]). - M. Martínez-Ramos, Instituto de Ecología, UNAM, Apdo. Post 27-3, Xangari, 58089, Mor. Mich., Mexico.

For more than a century, benthivorous fish such as common carp (Cyprinus carpio) have been introduced in many lakes worldwide for aquaculture and angling purposes. Although most studies focus on production aspects, research on the ecological effects of its introduction has been carried out for a long time (Cahn 1929); mostly indicating severe deterioration of the lake ecosystem (Cahoon 1953).

Perhaps the most conspicuous effect of these fish on shallow lakes is the increment of suspended solids, which has been shown to be closely related to fish biomass in experimental studies (Breukelaar et al. 1994). The increased concentration of suspended solids reduces light availability under water, affecting growth of submerged vegetation (Crowder and Painter 1991, Van Dijk and Van Vierssen 1991, Skubinna et al. 1995,
Hootsmans et al. 1996, Sidorkewicj et al. 1996). Since turbidity and submerged vegetation are key factors in the functioning of shallow lakes, understanding the effect of benthivorous fish on turbidity is crucial for understanding the impact of these animals on lake ecosystems. The fact that benthivorous fish play a key role in shallow lakes has been illustrated long ago by carp removal experiments (Cahoon 1953) and later by various biomanipulation experiments, resulting in vegetation recovery and enhanced transparency of the water (Rose and Moen 1952, Threinen and Helm 1954, Meijer et al. 1990, Hosper and Meijer 1993, Hosper 1994, Roberts et al. 1995).

Results from recent experimental studies on common carp suggest that effects are not linearly related to fish biomass. Instead, catastrophic changes were shown to

Accepted 21 March 2001

Copyright $(\subset)$ OIKOS 2001

ISSN 0030-1299

Printed in Ireland - all rights reserved 
appear at a particular fish biomass (Zambrano and Hinojosa 1999, Zambrano et al. 1999). These results suggest that benthivorous fish interactions with the system are more intricate than previously thought.

Here we present a model of the interaction between benthivorous fish and benthos, and its implications for turbidity, supported by data from experimental ponds. Our analyses suggest that there is a threshold in the density of fish, above which benthic populations collapse and turbidity increases sharply due to intensified feeding behavior.

\section{The model}

Effects of benthivorous fish on turbidity result largely from their feeding behavior (Breukelaar et al. 1994, Cline et al. 1994), and therefore depend upon their predator-prey interaction with benthic organisms. This interaction is surely a strong one in shallow systems as benthos can be reduced to very low densities by fish (Wilcox and Hornbach 1991, Zambrano et al. 1999). Searching for food, benthivorous fish resuspend solids from the bottom by sucking up the sediment and rejecting the non-food particles to the water (Lammens 1991). Obviously, higher densities of benthivorous fish result in more attacks to the bottom and more suspended solids in the water. However, the amount of resuspended sediments also depends on the foraging activity, which is likely to become higher at low prey density provided that the animals have no alternative food source to which they can switch (Abrams 1984, Werner and Anholt 1993). These aspects are captured in a minimal model describing the dynamics of fish, benthic organisms and turbidity in a simple way.

Interactions of benthivorous fish $(F)$ and benthic invertebrates $(B)$ are modeled using a simple LotkaVolterra predation-prey formulation. Benthic invertebrates (benthos for short) grow logistically but their abundance also depends on consumption $(\alpha)$ by fish.

$\frac{\mathrm{d} B}{\mathrm{~d} t}=r \cdot B \cdot\left(1-\frac{B}{k}\right)-\alpha$

Consumption by benthivorous fish $(\alpha)$ is based on a sigmoidal functional response. This seems to be the most reasonable option, as part of the benthos community will always be relatively difficult to reach by fish in this complex environment. Such a partial refuge effect leads to an upwardly bent prey isocline at low prey densities (cf. Fig. 1; e.g., Gotelli 1995), which can be modeled in various ways (Scheffer and de Boer 1995), the simplest of them is a type III functional response:

$\alpha=F \cdot g \cdot\left(\frac{B^{2}}{B^{2}+H^{2}}\right)$ where $g$ represents the maximum consumption rate of benthivorous fish and $H$ is a half saturation constant.

We are considering periods of time shorter than a fish generation; therefore benthivorous fish dynamics are based on individual growth without considering reproduction. These dynamics depend on efficiency of converting ingested food to biomass (e), consumption $(\alpha)$, and a loss rate $(l)$.

$\frac{\mathrm{d} F}{\mathrm{~d} t}=e \cdot \alpha-F \cdot l$

Dynamics of the suspended solids concentration $(S)$ depend on sinking $(P)$ and resuspension $(R)$ rates, and on the depth of the lake $(D)$ (Scheffer 1998).

(a)

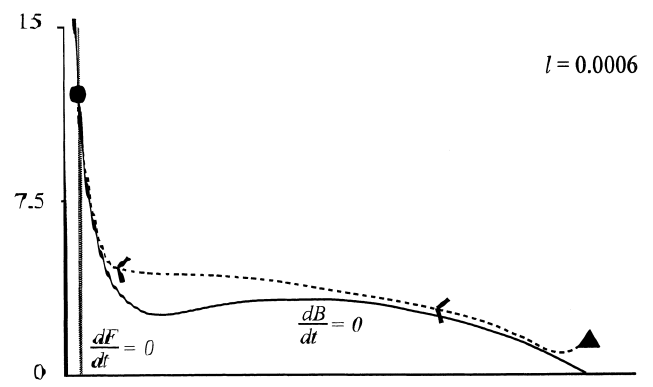

(b)

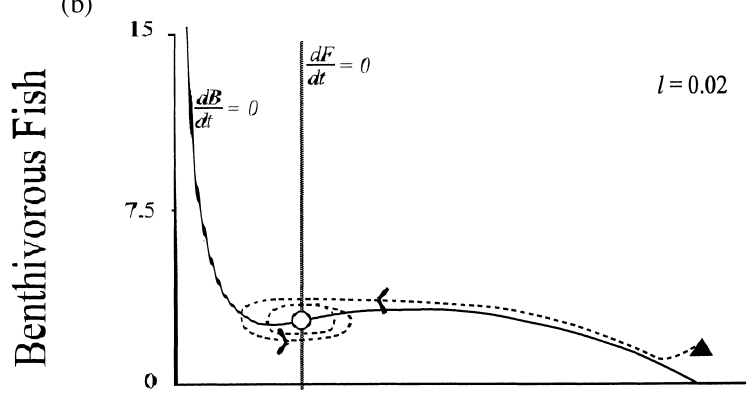

(c)

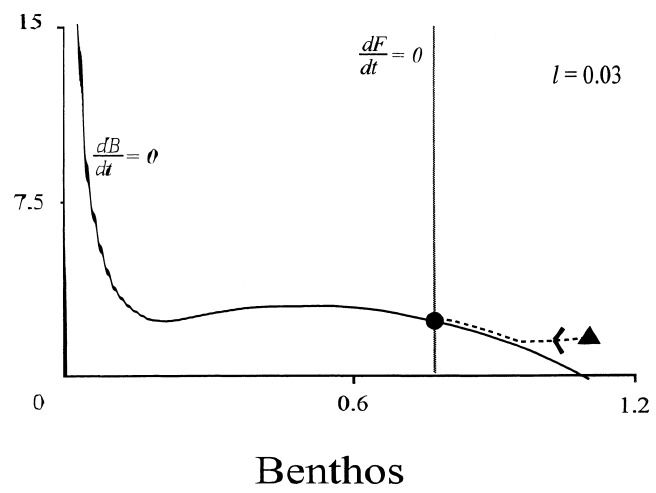

Fig. 1. Isoclines of benthivorous fish $(\mathrm{d} F / \mathrm{d} t=0)$ and benthos $(\mathrm{d} B / \mathrm{d} t=0)$, and transient dynamics from an initial state (triangle) to equilibria (solid dots). Panel a) represents default parameter setting, while panels b) and c) show effects of higher fish loss rate $(l)$ as indicated. 
Table 1. Parameters of the model obtained from the literature. $g$ and $e$ were obtained from Tacon and Cowey (1985), $H$ was obtained based on data from Weatherly and Gill (1987), $l$ was obtained based on data from Zambrano and Hinojosa (1999), $k$ was obtained based on data from Jeppesen et al. (1997), $r$ was obtained from Benke (1998), and $\lambda$ was tuned. See text for the meaning of symbols.

\begin{tabular}{ll}
\hline Parameter & Value \\
\hline$g$ & $0.05 \mathrm{~d}^{-1}$ \\
$H$ & $0.18 \mathrm{~g} \mathrm{~m}^{-2}$ \\
$e$ & 0.63 \\
$l$ & $0.0006 \mathrm{~d}^{-1}$ \\
$k$ & $1.1 \mathrm{~g} \mathrm{~m}^{-2}$ \\
$r$ & $0.5 \mathrm{~d} \mathrm{~d}^{-1}$ \\
$\lambda$ & $38 \mathrm{~g} \mathrm{~m}^{-2} \mathrm{~d}^{-1}$ \\
\hline
\end{tabular}

$\frac{\mathrm{d} S}{\mathrm{~d} t}=\frac{R}{D}-\left(\frac{P}{D}\right) \cdot S$

Because dynamics of suspended solids are much faster than benthos and fish dynamics, we simplify by assuming this variable to be always in equilibrium (Scheffer 1998).

$\stackrel{*}{S}=\frac{R}{P}$

Sediment resuspension may be caused by many processes, but for simplicity in the current model, we focus on the situation of fish foraging behavior as the dominant process, and neglect other causes of resuspension. The amount of solids that benthivorous fish stirs up while foraging is proportional to the area perturbed, which should increase roughly linearly with its food intake, while being inversely related to abundance of the prey, because more sediment needs to be 'worked through' per unit of food captured if the prey is sparse:

$R=\lambda \cdot\left(\frac{\alpha}{B}\right)$

where $\lambda$ is a scaling factor. Substituting this in eq. 5 and simplifying, we obtain a simple relationship between suspended solids concentration, and the abundance of benthivorous fish and benthos.

$\stackrel{*}{S}=\lambda \cdot\left(\frac{F \cdot g \cdot B}{B^{2}+H^{2}}\right)$

Parameter values, their dimensions and sources are shown in Table 1.

\section{Results}

The zero-growth isoclines of the fish-benthos model are rather classical (Fig. 1). The fish isocline is vertical, as no density dependent growth regulation other than through food is included in the model. The benthos isocline is humped due to the logistic growth formulation but is bent upward at the left-hand side as a result of the sigmoidal functional response of fish. For the default parameter setting (which corresponds to our best estimate of realistic parameter values) the vertical fish isocline intersects the benthos isocline in this upward bent left-hand part (Fig. 1a). In this case the intersection represents a stable equilibrium with low benthos biomass resulting from high fish predation pressure. Changes in the parameters modify the isocline picture, and can produce qualitatively different behavior. We do not discuss the general behaviour of this model in detail, as it does not differ from the classical predator-prey models. However, in order to check whether the qualitative outcome of the analysis would be sensitive to assumptions about default values of the parameters, we checked the effect of two factors that may vary considerably between systems: the loss rate of benthivorous fish $(l)$ and the carrying capacity for benthos $(k)$. The loss rate of fish may differ depending on temperature, activity and various mortality causes. Benthos carrying capacity depends largely on nutrient status but varies also with other factors such as lake depth (Jeppesen et al. 1997) and the presence of aquatic vegetation (Crowder and Painter 1991). Bifurcation analysis (Kuznetsov 1995) is used to produce a map of all possible types of asymptotic behavior of the model (Fig. 2). This diagram shows the border (bifurcation) between parameter regions with qualitatively different attractors. Stable and oscillating regimes are separated by a line representing so-called Hopf bifurcations. The

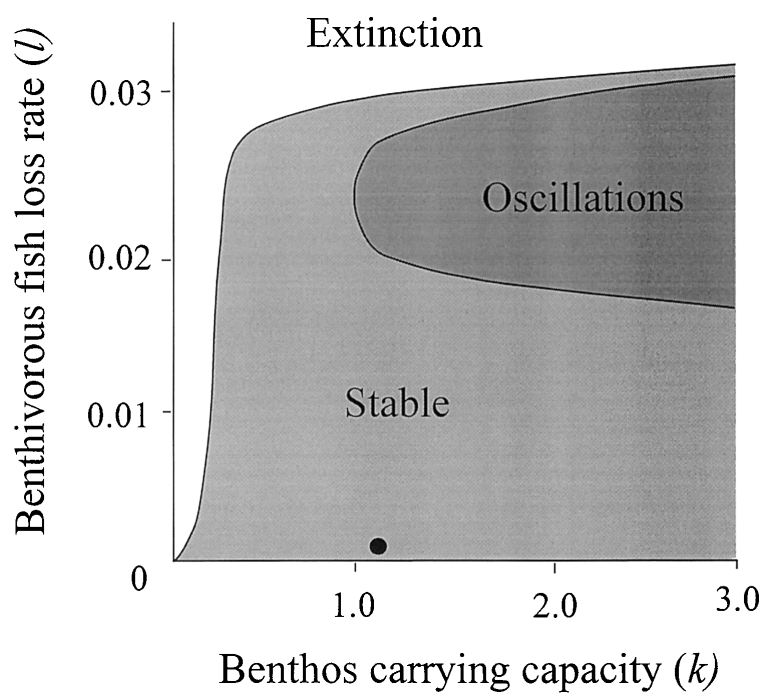

Fig. 2. Bifurcation diagram for the model showing for which combinations of benthos carrying capacity $(k)$ and fish loss rate $(l)$ we find stable coexistence, oscillating coexistence or extinction of the fish. The dot represents the default parameter values. 


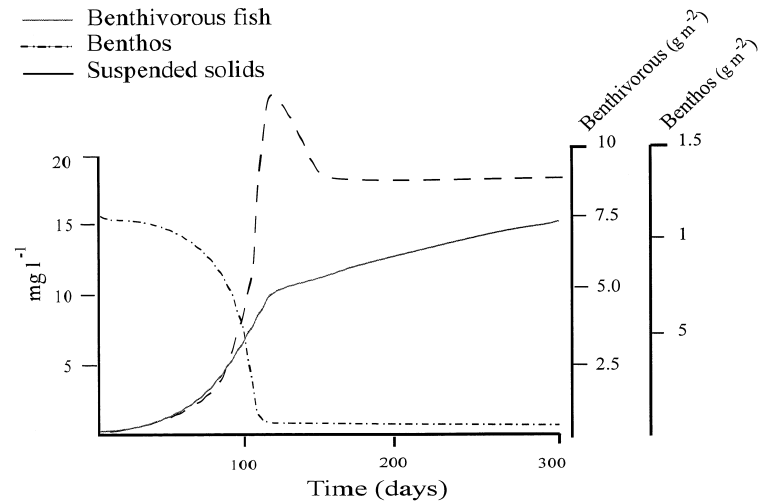

Fig. 3. Transient dynamics of carp, benthos and suspended solids for a simulation of $300 \mathrm{~d}$ corresponding to the trajectory plotted in Fig 1a.

transition from the stable state to extinction of fish at higher loss rates is indicated by the upper curve representing a so-called trans-critical bifurcation. The graph shows that the stable state with overexploited benthos populations occurs in a large parameter region around our default setting, suggesting that this may represent the typical situation in a wide range of systems.

We now take a closer look at the transient dynamics in this default situation. We simulate dynamics over $300 \mathrm{~d}$, starting from an initial state with a small amount of carp and a benthos population at carrying capacity. This is to mimic the typical situation in common carp cultures that we have studied in extensively managed ponds (see Zambrano et al. 1999).

With increasing fish biomass, benthos is predicted to decrease relatively smoothly until it reaches about $50 \%$ of its carrying capacity (Fig. 3). At this point a swift drop to quite a low benthos density occurs. The explanation for this discontinuity is the difference in growth rates between benthic invertebrates and benthivorous fish (Murdoch and Bence 1987). This results in a 'slowfast' predator-prey system in which the behavior can be understood by interpreting the isocline of the fast component (benthos) as a 'catastrophe fold' (Scheffer et al. 1995). Beyond the top of the isocline, the prey drops to an overexploited state, as described, for instance, in the classical work of Noy-Meir on grazing systems (NoyMeir 1975).

Suspended solids concentrations predicted by our eq. (7) for this simulation show a sharp increase coinciding with the collapse of benthos. This is due to the assumed increase in foraging intensity, resulting in a larger quantity of sediment disturbed by benthivorous fish at reduced benthos densities. Obviously, starting with smaller initial carp densities it takes longer to reach the critical biomass for overexploitation of benthos, and the switch to higher suspended solid concentrations occurs later. These predicted dynamics correspond well to observations in experimental carp ponds (Roberts et al. 1995, Zambrano and Hinojosa 1999). In these ponds, introduced carp initially produce little change in turbidity, until a switch to a turbid state occurs, supposedly when carp individuals have grown enough to reach a particular critical biomass in the pond. This switch occurs earlier in ponds starting with a higher initial biomass of carp (Fig. 4).

The sudden switch to a turbid condition is not predicted to occur by the model for situations with a low benthos carrying capacity as seems more likely for less productive and for deeper lakes (Fig. 5).

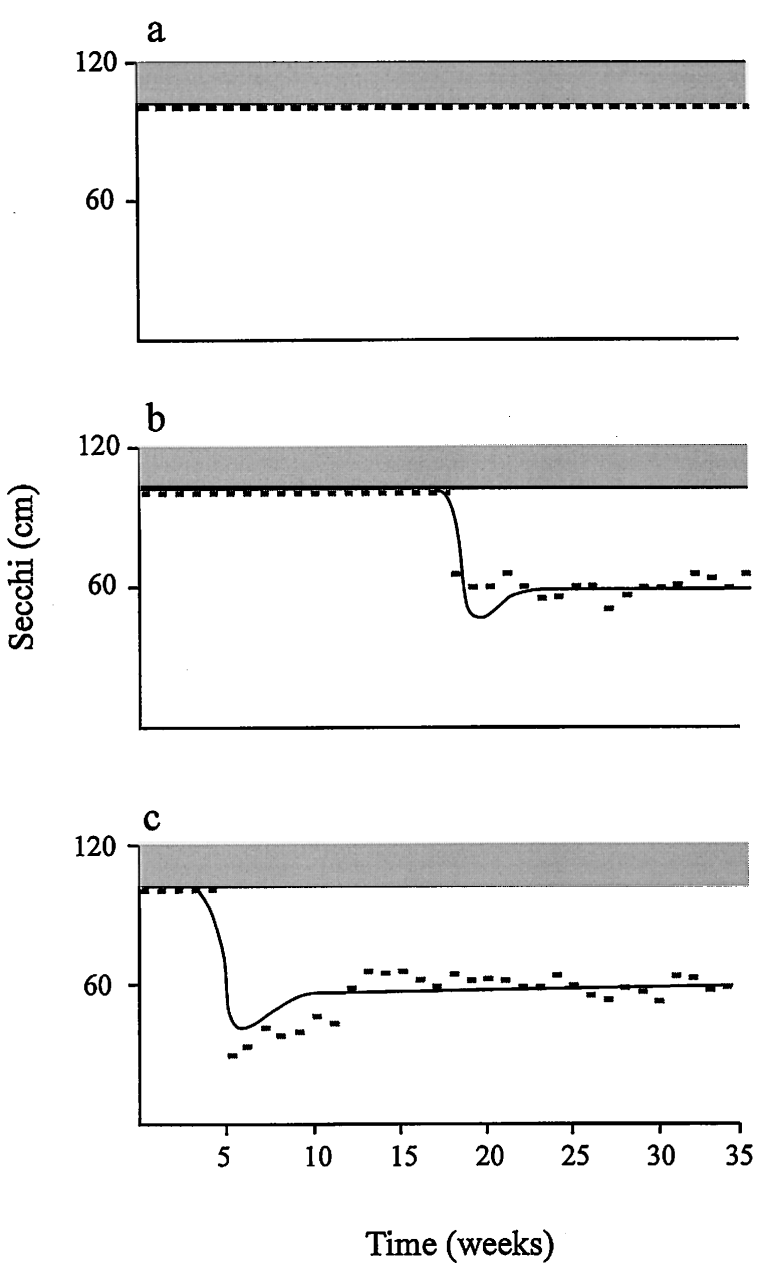

Fig. 4. Time series of Secchi depth in experimental ponds (data points) compared with model simulation results (solid lines). Carp abundances were 0.2, 0.8, and 1.2 ind. $\mathrm{m}^{-2}$ in experiments represented by panels a, b and c, respectively. Model simulations started with initial carp densities of 0.001 , 0.11 , and $1.5 \mathrm{~g} \mathrm{~m}^{-2}$ in panels $\mathrm{a}, \mathrm{b}$ and $\mathrm{c}$, respectively. Suspended solids concentrations computed by the model were transformed to Secchi depth values using a regression model based on data from the experimental ponds (Zambrano et al. 1999). Shadowed zones indicate non-detectable Secchi values in the ponds that were only $1 \mathrm{~m}$ deep. 


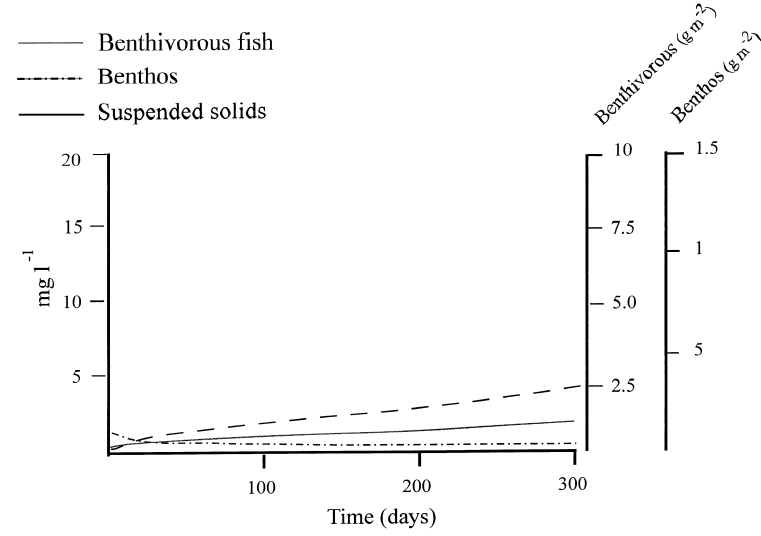

Fig. 5. Transient dynamics of carp, benthos and suspended solids for a simulation for a less productive system represented by a lower benthos carrying capacity $(k=0.1)$.

\section{Discussion}

The close correspondence between the dynamics of experimental ponds and the model results suggests that the presented model may indeed capture the essence of the way in which benthivorous fish affects benthos and suspended solids in such shallow eutrophic systems. Also, the observation that benthivorous fish effects can be minor in less productive lakes may explain contradictory carp effects observed in different types of systems (Bales 1992). Certainly, all documentation of large impact of benthivorous fish on turbidity and vegetation comes from eutrophic shallow lakes and ponds (Scheffer 1998).

The prediction that benthivorous fish has little effect as long as its biomass remains below a certain critical limit is especially relevant from the viewpoint of fish removal ('biomanipulation') as a way to restore turbid shallow lakes to a clear state. Indeed, a recent evaluation of 18 case studies of biomanipulation in eutrophic Dutch shallow lakes dominated by cyprinids provides support for the idea that there is a sharp critical threshold. All lakes from which less than $70 \%$ of the fish biomass was removed remained turbid, whereas nine out of ten lakes where fish biomass was reduced below $30 \%$ cleared up sufficiently to obtain bottom view (Meijer et al. 1999). This sharp distinction supports the idea that there is a critical fish density beyond which turbidity rises steeply. Remarkably, the critical fish density at which turbidity increases in our very simple model also corresponds to about $30 \%$ of the carrying capacity for eutrophic systems (Figs. 1a, 3).

Although the field patterns thus correspond well to the predictions from the model, other mechanisms may cause similar patterns in practice. For instance, a sudden increase in turbidity could result from a synchronous switch in fish behavior. Indeed, potentially benthivorous fish such as carp only switch from planktonic food to benthos beyond a certain critical size depending on the availability of these resources (Lammens 1991). Such a switch cannot explain the patterns in the studied carp ponds or the biomanipulated lakes as in all cases fish were benthivorous in the clear as well as in the turbid phase. Another potential explanation would be a switch from benthic food to aquatic plants, the latter triggering excessive sediment erosion. Again, this is unlikely as in the studied ponds carp started consuming vegetation only after the switch (Zambrano unpubl.), and in biomanipulated lakes, vegetation often occurs months or even years after the switch from turbid to clear (Meijer et al. 1999). Also, a sudden change in behavior (e.g. fighting) at high densities is unlikely, as carp are regularly kept at much higher densities without showing excessive inference behavior. Another alternative hypothesis could be that beyond a certain critical damage to the sediment surface caused by fish, the sediment becomes vulnerable to resuspension by wind-induced waves (Scheffer 1998). However, in the carp pond study, wind speeds were always very low and wave resuspension played no role.

Obviously, other possible hypotheses may be thought of that we did not mention. One way to check the plausibility of our particular hypothesis further is to scrutinize its ingredients in more detail. Two key assumptions for the generated switch in the model are: 1) relative impact of fish on turbidity is inversely related to benthos density due to an increase in foraging activity; and 2) benthos populations collapse to an overexploited state when fish biomass exceeds a critical threshold. The first assumption seems reasonable assuming an increase of foraging activity with a depletion of resources (Werner and Anholt 1993). This reduces risk of starvation in unpredictable food intake environments (Krebs and Davies 1991), and is consistent with previous work on benthivorous fish foraging (Lagler et al. 1977, Pitcher and House 1987). Indeed, carp populations persist at very low benthos densities (Zambrano et al. 1999), and one would expect them to search relatively intensively under such conditions to meet their metabolic needs. However, the exact relationship between prey density and search intensity of carp remains to be explored. Also the second assumption is testable and would be worth exploring in future work.

Importantly, the effect of carp and other benthivorous fish goes beyond the resuspension effect addressed in our minimal model. Other pathways such as enhanced nutrient recycling from the sediment and cascading effects, may result in an increase of phytoplankton abundance, enhancing the impact of fish on turbidity (Lamarra 1974, Andersson et al. 1988, Havens 1993). The generated turbidity also affects behavior of visually hunting predators and mating fish (Miner and Stein 1993). But, as mentioned earlier, one of the most notorious consequences of high densities of benthivorous fish is that submerged vegetation tends to disappear. This is due to increased turbidity, but also 
consumption and uprooting (King and Hunt 1967, Crivelli 1983). Since submerged vegetation enhances water clarity through a suite of mechanisms the disappearance of vegetation implies a feedback that promotes turbidity even further. The switch from a vegetated clear-water state to a turbid condition coincides with a tremendous loss of biodiversity of birds, fish and invertebrates in shallow lakes (Scheffer 1998).

In view of the apparent key role of benthivorous fish in the deterioration of these ecosystems with eutrophication it seems worthwhile investigating the mechanisms suggested by the presented analyses further. Especially, the prediction that there is a critical fish biomass below which effects are minor and the suggestion that the dramatic benthivorous fish impact should be mostly in eutrophic shallow systems, indicate ways to focus management strategies aimed at minimizing the potentially huge impact of carp and other benthivorous fish.

Acknowledgements - Thanks to Egbert van Nes for his collaboration in the Hopf bifurcation analysis.

\section{References}

Abrams, P. A. 1984. Foraging time optimization and interactions in food webs. - Am. Nat. 124: 80-96.

Andersson, G., Granéli, W. and Stenson, J. 1988. The influence of animals on phosphorus cycling in lake ecosystems. - Hydrobiologia 170: 267-284.

Breukelaar, A., Lammens, E., Klein Breteler, J. G. P. and Tatrai, I. 1994. Effects of benthivorous bream (Abramis brama) and carp (Cyprinus carpio) on sediment resuspension and concentrations of nutrients and chlorophyll $a$. Freshwat. Biol. 32: 112-121.

Bales, M. 1992. Carp and river environment deterioration, villain or innocent by stander? - Newsl. Aust. Soc. Fish Biol. 22: 26-27.

Benke, A. C. 1998. Productive dynamics of riverine chironomids: extremely high biomass turnover rates of primary consumers. - Ecology 79: 899-910.

Cahn, A. R. 1929. The effect of carp on a small lake: the carp as dominant. - Ecology 10: 371-374.

Cahoon, W. G. 1953. Commercial carp removal at Lake Mattamuskeet, North Carolina. - J. Wildl. Manage. 17: 312-316.

Cline, J. M., East, T. L. and Threlkeld, S. T. 1994. Fish interactions with the sediment-water interface. - Hydrobiologia 275/276: $301-312$.

Crivelli, A. J. 1983. The destruction of aquatic vegetation by carp Cyprinus carpio a comparison between southern France and the USA. - Hydrobiologia 106: 37-42.

Crowder, A. J. and Painter, D. S. 1991. Submerged macrophytes in Lake Ontario: current knowledge, importance, threats to stability, and needed studies. - Can. J. Fish. Aquat. Sci. 48: 1539-1545.

Gotelli, N. J. 1995. A primer of ecology. - Sinauer.

Havens, K. E. 1993. Responses to experimental fish manipulations in a shallow, hypereutrophic lake: the relative importance of benthic nutrient recycling and trophic cascade. Hydrobiologia 254: 73-80.

Hootsmans, M. J., Drovandi, A. D., Soto Perez, N. and Weigman, F. 1996. Photosynthetic plasticity in Potamogeton pectinatus L. from Argentina: strategies to survive adverse light conditions. - Hydrobiologia 340: 1-5.
Hosper, H. 1994. An ecosystem-based approach for the restoration of shallow lakes in the Netherlands. - Lake Reservoir Manage. 9: 82

Hosper, H. and Meijer, M.-L. 1993. Biomanipulation, will it work for your lake? A simple test for the assessment of chances for clear water, following drastic fish-stock reduction in shallow, eutrophic lakes. - Ecol. Engineering 2: $63-72$.

Jeppesen, E., Jensen, J. P., Sondergaard, M. et al. 1997. Top-down control in freshwater lakes: the role of nutrient state, submerged macrophytes and water depth. - Hydrobiologia 342/343: $151-164$.

King, D. R. and Hunt, G. S. 1967. Effect of carp on vegetation in Lake Erie Marsh. - J. Wildl. Manage. 31: 181-188.

Krebs, J. R. and Davies, N. B. 1991. An introduction to behavioural ecology. - Blackwell Scientific.

Kuznetsov, Y. A. 1995. Elements of applied bifurcation theory. - Springer-Verlag.

Lamarra, V. A. 1974. Digestive activities of carp as a major contributor to the nutrient loading of lakes. - In: Marshall, K. E. (ed.), XIX Congress International Association of Limnology, Winnipeg, Canada, Aug. 22-29, 1974. Freshwater Inst., Dept of Environment.

Lammens, E. H. R. R. 1991. Diets and feeding behaviour. In: Winfield, I. J. and Nelson, J. S. (eds), Cyprinid fishes: systematics, biology and exploitation. Chapman and Hall, pp. 353-376.

Lagler, K. F., Bardach, J. E., Miller, R. R. and Passino, D. R. M. 1977. Ichthyology. - John Wiley \& Sons.

Meijer, M.-L., De Haan, M. W., Breukelaar, A. W. and Buiteveld, H. 1990. Is reduction of the benthivorous fish an important case of high transparency following biomanipulation in shallow lakes? - Hydrobiologia 200/201: 303315.

Meijer, M.-L., De Boois, I., Scheffer, M. et al. 1999. Biomanipulation in shallow lakes in The Netherlands: an evaluation of 18 case studies. - Hydrobiologia 409: 13-30.

Miner, J. G. and Stein, R. A. 1993. Interactive influence of turbidity and light on larval bluegill (Lepomis macrochirus) foraging. - Can. J. Fish. Aquat. Sci. 50: 781-788.

Murdoch, W. W. and Bence, J. 1987. General predators and unstable prey populations. - In: Kerfoot, W. Ch. and Sih, A. (eds), Predation, direct and indirect impacts on aquatic communities. Univ. Press of New England, pp. 17-29.

Noy-Meir, I. 1975. Stability of grazing systems an application of predator prey graphs. - J. Ecol. 63: 459-482.

Pitcher, T. J. and House, A. C. 1987. Foraging rules for group feeders: area copying depends upon food density in shoaling goldfish. - Ethology 76: 161-167.

Roberts, J., Chick, A., Oswald, L. and Thompson, P. 1995. Effect of carp, Cyprinus carpio L., an exotic benthivorous fish, on aquatic plants and water quality in experimental ponds. - Mar. Freshwat. Res. 46: 1171-1180.

Rose, E. T. and Moen, T. 1952. The increase in game-fish populations in east Okoboji Lake, Iowa, following intensive removal of rough fish. - Trans. Am. Fish. Soc. 82: 104-114.

Scheffer, M. 1998. Ecology of shallow lakes. 1. - Chapman and Hall.

Scheffer, M. and de Boer, R. J. 1995. Implications of spatial heterogeneity for the paradox of enrichment. - Ecology 76: $2270-2277$.

Scheffer, M., Baveco, J. M., DeAngelis, D. L. et al. 1995. Stunted growth and stepwise die-off in animal cohorts. Am. Nat. 145: 376-388.

Sidorkewicj, N. S., Lopez-Carzola, A. C. and Fernández, O. A. 1996. The interaction between Cyprinus carpio L. and Potamogeton pectinatus L. under aquarium conditions. Hydrobiologia 340: 271-275.

Skubinna, J. P., Coon, T. G. and Batterson, T. R. 1995. Increased abundance and depth of submersed macrophytes 
in response to decreased turbidity in Saginaw bay, Lake Huron. - J. Great Lakes Res. 21: 476-488.

Tacon, A. G. J. and Cowey, C. B. 1985. Protein and amino acid requirements. - In: Tytler, P. and Calow, P. (eds), Fish energetics. New perspectives. Croom Helm, pp. 155-183.

Threinen, C. W. and Helm, W. T. 1954. Experiments and observations designed to show carp destruction of aquatic vegetation. - J. Wildl. Manage. 18: 247-251.

Van Dijk, G. M. and Van Vierssen, W. 1991. Survival of a Potamogeton pectinatus L. population under various light conditions in a shallow eutrophic lake Lake Veluwe in The Netherlands. - Aquat. Bot. 39: 121-130.

Weatherly, A. H. and Gill, H. S. 1987. The biology of fish growth. - Academic Press.
Werner, E. E. and Anholt, B. R. 1993. Ecological consequences of the trade-off between growth and mortality rates mediated by foraging activity. - Am. Nat. 142: 242-272.

Wilcox, T. P. and Hornbach, D. J. 1991. Macrobenthic community response to carp (Cyprinus carpio L.) foraging. - J. Freshwat. Ecol. 6: 171-183.

Zambrano, L. and Hinojosa, D. 1999. Direct and indirect effects of carp (Cyprinus carpio) on macrophytes and benthic communities in experimental shallow ponds in central Mexico. - Hydrobiologia 408/409: 131-138.

Zambrano, L., Perrow, M. R., Macias-Garcia, C. and AguirreHidalgo, V. 1999. Impact of introduced carp (Cyprinus carpio) in subtropical shallow pond in central Mexico. - J. Aquat. Ecosyst. Stress Recovery 6: 281-288. 